\title{
AC 2010-1352: WHAT DO EMPLOYERS WANT IN TERMS OF EMPLOYEE KNOWLEDGE OF TECHNICAL STANDARDS AND THE PROCESS OF STANDARDIZATION?
}

Bruce Harding, Purdue University

Paul McPherson, Purdue University 


\title{
WHAT DO EMPLOYERS WANT IN TERMS OF EMPLOYEE KNOWLEDGE OF TECHNICAL STANDARDS AND THE PROCESS OF STANDARDIZATION?
}

\begin{abstract}
Products and processes considered everyday conveniences would not be possible without standardization. That standardization making today's technology possible was developed over the last few decades by practitioners, many of whom are on the brink of retirement. Consequently, a growing concern exists among standards practitioners and standards developing organizations (SDOs) alike as to the source of the next generation of standards expertise.
\end{abstract}

Over the last decade standards developing organizations and educational institutions alike endeavored to foster standards education by developing multidisciplinary curricula directed toward advanced education on standardization. While studies have been initiated within academia to determine the current use of standards in the classroom, numerous impediments remain to growing this area of education.

The study discussed in this paper was undertaken in 2009 by Purdue University to determine both the demand by industry for engineering practitioners possessing standardization expertise prior to employment, and also the interest in industrial collaboration with local colleges and universities to establish courses on standardization.

This paper presents the results based on industry segments. These include alternative energy, automotive, aerospace, computers and electronics, construction, medical, military/ government and health/public safety.

\section{Standards in practice today}

Practitioners of the 'baby boomer' generation are generally the standardization experts of today. As that generation begins to retire, there seems to be waning interest among recent engineering or technology graduates to fill the looming void in standardization expertise.

Despite the daily interaction humans have with standardized products or processes, rarely is the time taken to consider the various standards that form the foundation of products and process development, let alone why such requirements are even necessary. For example, without standardization, telephony among cellular phones across different carriers would simply not be possible. Yet even among technical users, the assumption is that phones will just work -- society simply takes it for granted. Is this lack of knowledge about the importance of standardization hindering both new creation and innovation within American companies? In order for innovation to occur, it is imperative that one not just accept items at face value, but rather continually question the specifications and processes that go into developing such items. Despite this apparent lack of interest, standards continue to affect every aspect of today's society and economy, from basic electronic devices, to the financial sector, and global trade. 
Only in recent years have United States standards professionals developed a growing concern regarding the lack of student exposure and knowledge about the use, implementation and development of standards. In 2005, the United States Standards Strategy (USSS) was formally approved by the American National Standards Institute (ANSI). ANSI, a nonprofit nongovernment organization, serves as the national standardizing body representing the United States. SDOs write standards while ANSI certifies standards as meeting the criteria to be an American National Standard (ANS).

Increasing educational awareness about standardization is one of twelve primary objectives of the USSS (1). To that end, over the past several years standards professionals have conducted studies to determine how professors are incorporating standards into current curriculums. In parallel, other attempts have been made to increase students' awareness of standards by imposing minimal requirements for standards use within specific engineering and technology ABET requirements. Yet the question of how to adequately implement the practice and application of standards into curriculums still remains largely unanswered.

Among standards professionals attending the 2009 "Promoting Education about Standardization" forum held at the National Institute of Standards and Technology (NIST) campus, one common suggestion was to offer a multidisciplinary course to expose students to both a variety of standards and procedures within standards development organizations. While the need for such a course was generally agreed upon, the question of specific techniques for integrating such a course was avoided. This was due to the practical difficulties created by attempting to add courses to curricula already overflowing with required courses. Thus, despite efforts to increase education about standards, it is recognized that progress will be slow.

Another technique posed was that of incorporating standards-based modules throughout multiple courses, negating the need to add credit hours to already bloated curricula. This too was seen as a positive approach, but the development of, and access to, sufficient discipline-specific course material was seen as a major hurdle.

\section{Current educational offerings}

Compared to other developed countries, the United States is far behind development of standards curricula appropriate for all ages. A number of European Union countries plus Japan, China, and Korea, have already discovered the importance of standards education and are now seeing benefits of implementing standards-awareness courses into all levels of education, including grade schools (2). Among implementers, it is felt that through early awareness of the importance of standards, students entering the workforce within these countries will become an essential asset to companies in a growing global economy. Examples of the international education courses include the "87 standardization courses held at 46 Korean universities" in 2006 which "were attended by 6,681 students," the Asian Link Project on Standardization Education, and a "secondary school program on standardization education in Thailand (2003-2006), where 2,354 teachers were trained and 444,600 students received standardization education" (2). However among these success stories, there are major roadblocks when considering these approaches in the United States. The complexity of the US decentralized standards system and the lack of government funding commitments enjoyed by other countries are examples. 
Currently within the United States, there are very few avenues to standardization education. These include either on-job training sessions, typically to specific standards, general courses held by major standards development organizations (SDOs), or by enrollment in specific graduate courses at one of only four universities (The Catholic University of America, University of Colorado at Boulder, Purdue University, and the University of Pittsburgh) (1). At this writing these universities are the only US institutions that offer courses dedicated to advanced knowledge / understanding of the standardization processes (American National Standards Institute, 2009).

While on-the-job training is currently the main method for engineers to advance their standards education, the opportunity may not be available to all employees. In addition to ANSI, major SDOs, such as IEEE (The Institute of Electrical and Electronics Engineers), ISO (The International Organization for Standardization), and ASTM, Inc. (formerly the American Society for Testing and Materials) and ASME (American Society of Mechanical Engineers) offer online and on-site training as well as educational resources such as case studies and tutorials for the average individual interested in standards education. While the above-named universities offer courses specifically on standardization, these courses are neither required for, nor target, undergraduate students. Other more generalized standards resources, available to the public can be found at www.standardslearn.org, www.standards.gov, and www.ses-standards.org.

One reason for the lack of courses is funding. Many professionals agree that an adequate standards course would require students to have unlimited access to a standards database which can cost tens of thousands of dollars. While there are many educational grants available, few are designed to assist in developing a course focused on standards. Without a college or university willing to absorb the cost of establishing such a course, there are very few methods of funding. Both ASTM and ISO have developed awards for educational institutions or professors who incorporate the use of standards as an integral part of classroom assignments. In 2009, ASTM introduced the "professor of the year" award in which both the professor and the university receive monetary awards. In 2006, ISO in conjunction with the Japanese Industrial Standards Committee introduced a "Higher Education in Standardization" award which includes a 15,000 Swiss franc cash prize and a publication in both ISO's Focus Magazine and website (3).

\section{Study methodology}

With this rationale in mind, in 2009 a study was conducted by Purdue University to determine both industry need for college graduates who possess the skills and knowledge to implement standards and/or develop standards, plus industry willingness to contribute to the development of standards courses.

Since standards affect all economic sectors, from manufacturing to financial industries, a questionnaire was developed that targeted managers from multiple sectors of society, but with an emphasis on technical industries. In that effort, a survey questionnaire was sent to members of ASTM, alumni of the Purdue University College of Technology, and industry contacts as listed by the National Society of Professional Engineers (NSPE). See Appendix A. The survey targeted individuals holding management positions, likely the decision-makers who could provide the most accurate information regarding each company's use of standards. However the directions allowed managers to delegate completing the survey to others who might be more directly 
knowledgeable about standards use and/or interest within their company. Of the approximately 13,000 individuals receiving the survey, 737 responded. About 450 indicated that they held managerial positions. The Purdue University Development Office which controls surveying of graduates, indicates that the response rate of $<6 \%$ is typical of such surveys.

The University's rules on surveys to graduates required this 'blind contact' technique rather than one drilling down to more specific job titles, as the latter would have required specific permission of individual employers.

It is acknowledged that the respondents of this survey may yet be too limited a subset of standards stakeholders. A follow-up survey will be sent in 2010 to Purdue graduate "managers" who are alumni of not only the College of Technology, but also the College of Engineering, the College of Business and the College of Science. The second survey is expected to reach approximately 50,000 potential respondents.

\section{Survey results}

\section{Managers recognize standardization as essential to daily operations, regardless of} the company's economic sector. See Figure 1.

The survey confirms that respondents consider standards a key driving force behind their company's growth and that employees have multiple opportunities to attend training sessions on

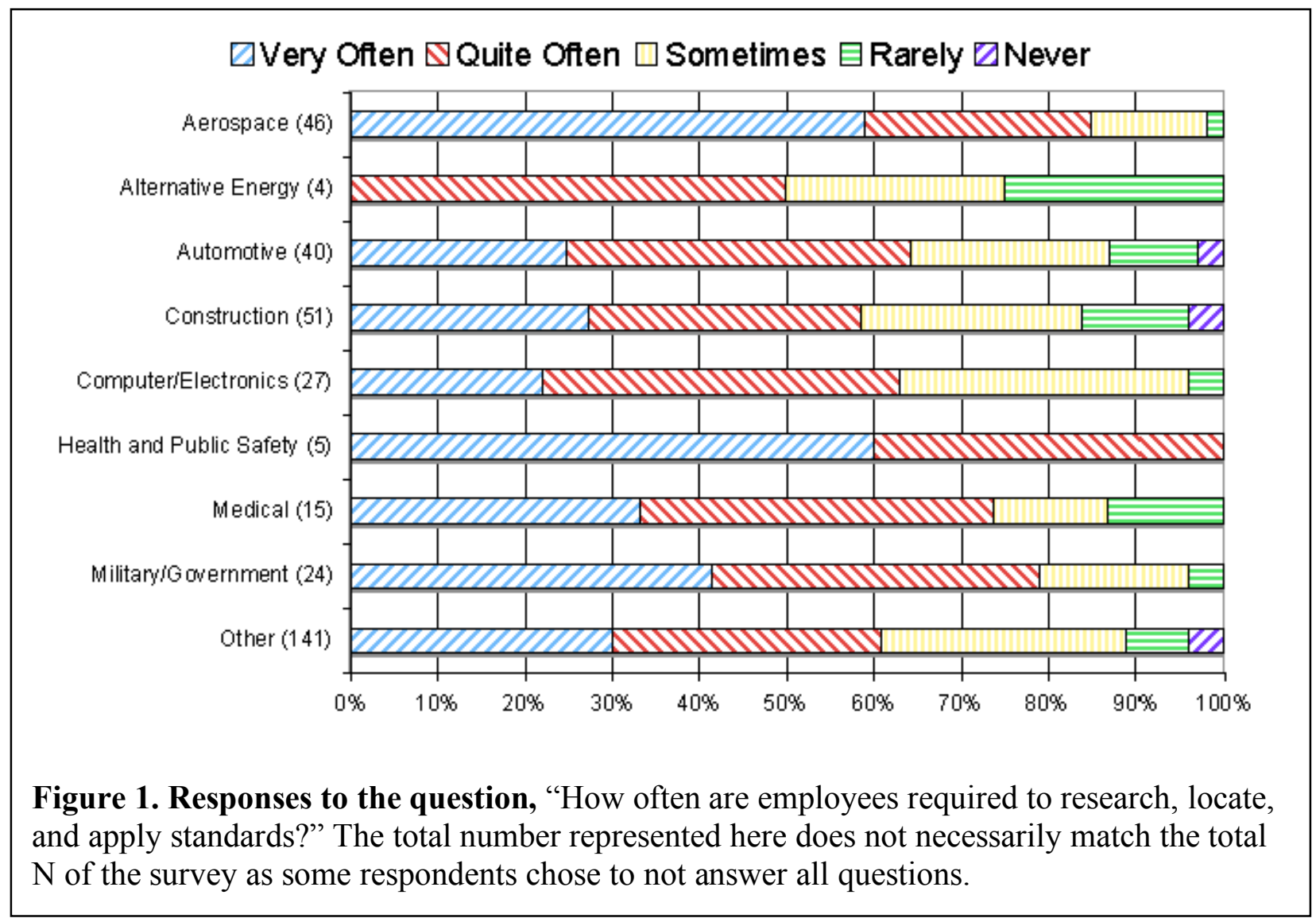


standardization. Sixty-five percent of those surveyed indicated that there are employees in the organization who are either active participants within standards development organizations or active participants on standards committees. Additionally, ninety percent of those surveyed described standardization (company standards and/or national/international standards) as being either extremely, or very, important in the overall growth and success of the company, its processes, products, and services. Furthermore, eighty-seven percent of respondents report that the standards necessary to complete projects are readily accessible.

However, despite this apparent understanding of the importance of standards, only sixty percent of the respondents claim that their companies offer courses or other training opportunities for employees to increase their knowledge about the standards development / standardization process. Of those who reported on-site training, sixty-one percent offer courses multiple times a year, while nine percent offer daily training. In addition, seventy-four percent of the companies offering on-site training also suggest that employees attend standardization sessions offered by external organizations. Of the respondents that indicated their companies do not offer courses and training opportunities, sixty-three percent indicated employees attend training sessions offered by external organizations. Only thirty-two percent of those surveyed indicated that these training sessions are required for all employees.

\section{There is a need to develop more courses which incorporate standardization as part} of the curriculum at institutions of higher learning. See Figure 2.

While an overwhelming majority (eighty-five percent) of respondents believe that current

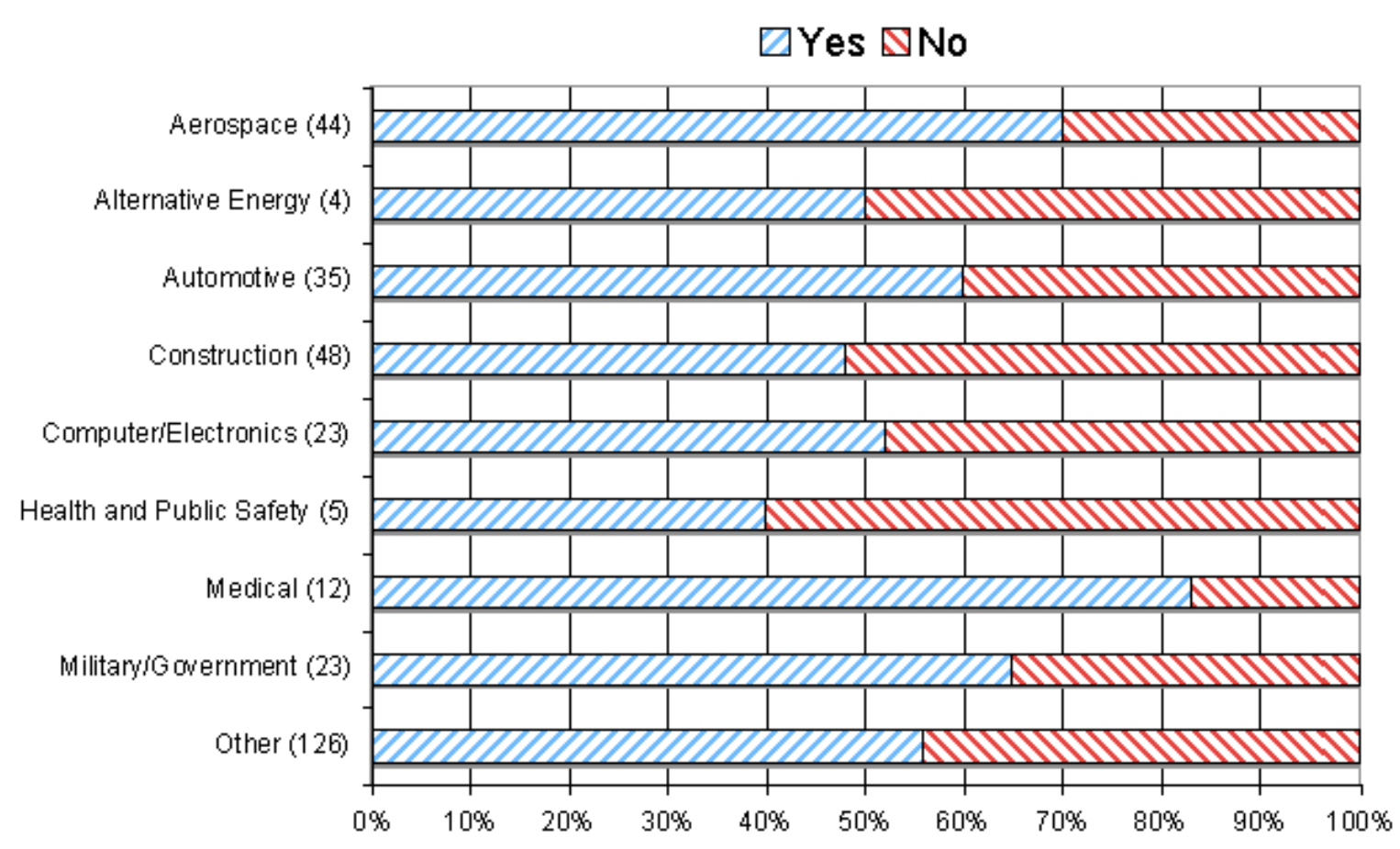

Figure 2. Responses to the question, "Is there a need for engineers who possess the fundamentals of standards development and the knowledge to find and apply standards prior to employment?" The total number represented here does not necessarily match the total $\mathrm{N}$ of the survey as some respondents chose to not answer all questions. 
employees meet company expectations when determining what type of standard to use, how to locate the standard, and how to utilize the standard, the majority (fifty-eight percent) agree that there is a need for engineers who possess the fundamentals of standards development and the knowledge to find and apply standards prior to employment. Seventy-eight percent of those surveyed agreed that taking a standards education course in colleges or high schools which is focused on both the development and the application of standards, would better prepare graduates to work for their company. The majority (fifty-two percent) of respondents also indicated that such a course could potentially reduce the amount of on-site training. However, due to the diversity of both respondent job titles and industry sectors represented, the results strongly suggest a general need for such a course to be multidisciplinary. Company size of respondents ranged from self-employed individuals to employees of large multinational corporations.

\section{There is a significant lack of industry funding for education about standardization. See Figure 3.}

Despite company representatives being in favor of implementing a course on standardization into higher education curriculums, only fifty-three percent of respondents felt that their company

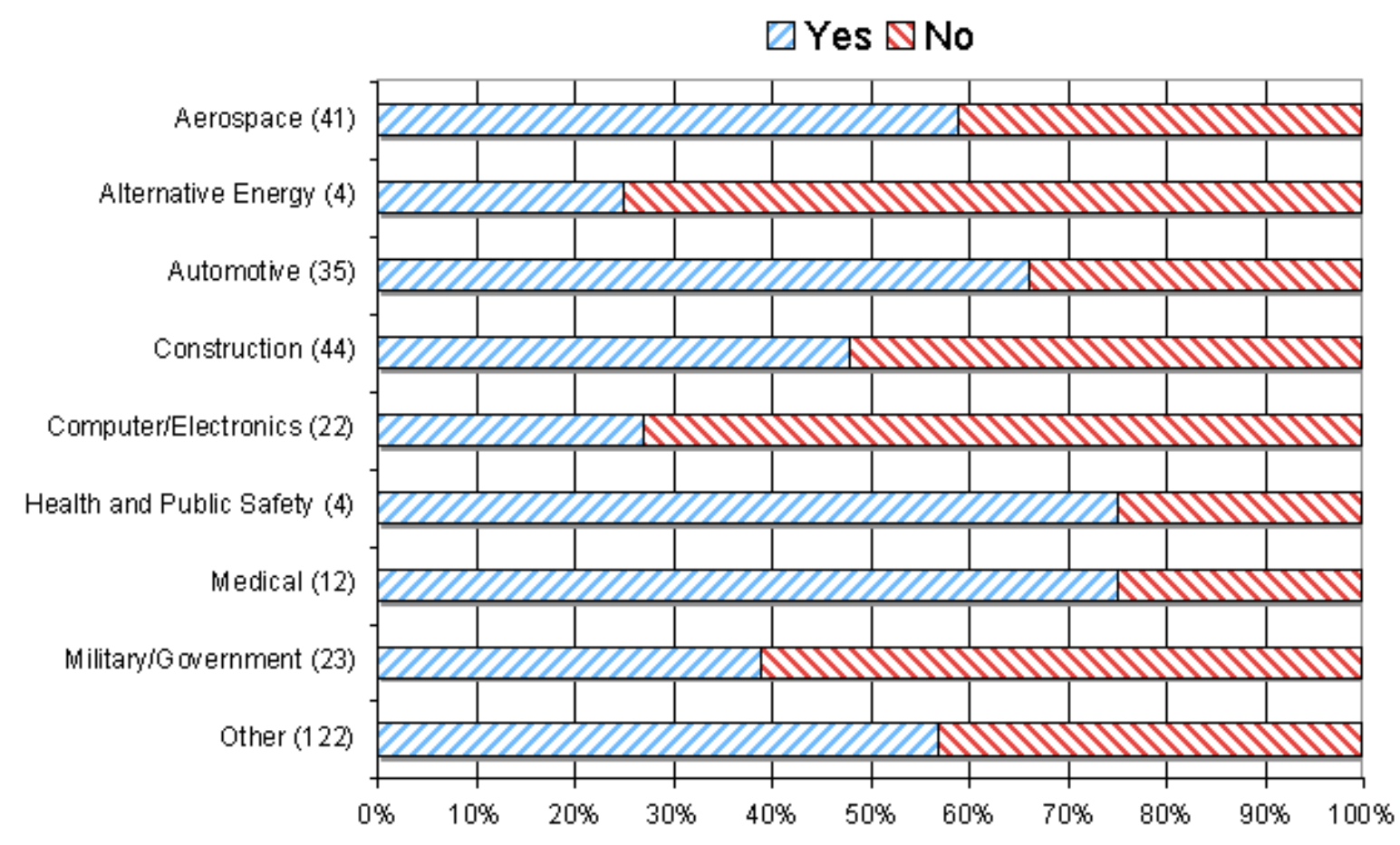

Figure 3. Responses to the question, "Would this company be willing to work with local educational institutions to establish a curriculum in which more focus is placed on implementing education about standardization?" The total number represented here does not necessarily match the total $\mathrm{N}$ of the survey as some respondents chose to not answer all questions.

would be willing to work with local educational institutions to establish a course dedicated to education about standardization. The majority indicated that either there was little to no funding 
available based on the state of the current economy, or the respondent was unsure whether or not such funding could be incorporated into the company budget.

For those few individuals who suggested that their company might be willing to work with local educational institutions, funding ranged from $\$ 200$ per person per session, to upwards of donations totaling $\$ 500,000$. Additionally some individuals suggested rather than monetary

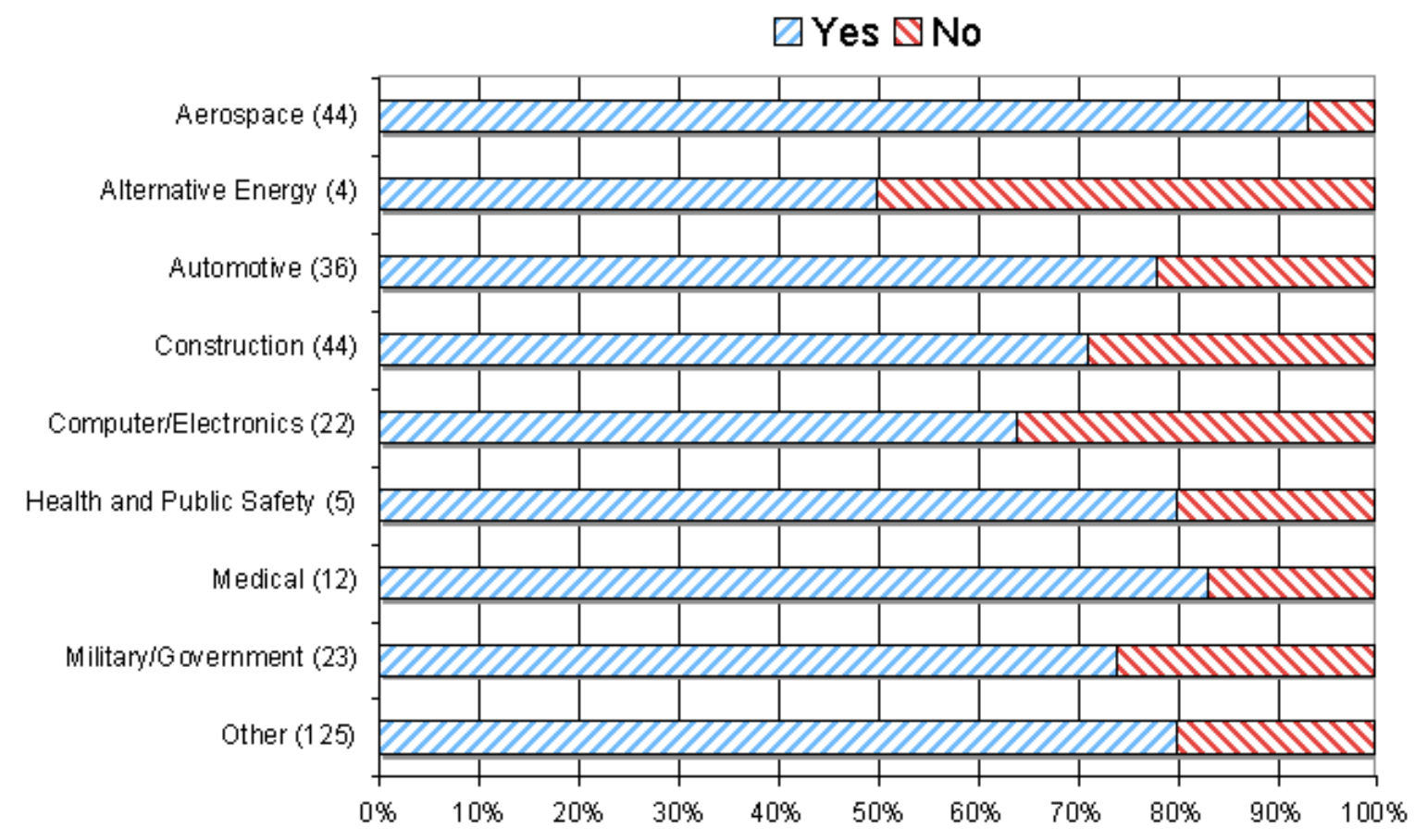

Figure 4. Responses to the question, "In your opinion would taking a standards education course within colleges, universities, or high schools that focuses on both the development and the application of standards better prepare graduates to work for this company?" The total number represented here does not necessarily match the total $\mathrm{N}$ of the survey as some respondents chose to not answer all questions.

contribution, they would be willing to assist on an advisory basis. Other suggested sources of potential funding included state and federal government grants. The lack of funding from industry or others poses a challenging hurdle to growing such courses. There is often significant expense required to make standards available to students via either outright institutional purchase or a subscription service.

Regardless of the willingness of some segments to fund such efforts at point in time, all segments with exception of alternative energy, concur in a rather dramatic fashion that there should be standards education coursework to better prepare graduates. See Figure 4. 


\section{Course proposal}

Based on these results, and in order to appeal to the broadest possible industry sectors plus provide the suggested multidisciplinary classroom environment, it is recommended that standards professionals work with colleges and universities to develop a two-term "core" course for undergraduate upperclassmen available to all majors. Throughout the first course, students would be introduced to the concept of standards, their economical importance, the major standards developing organizations, and the process by which standards are developed and approved. Furthermore, students would be required to select a specific standards developing organization, not covered in lectures, that relates to their major and give a presentation covering not only the standards applicable, but also the standards development process and the organization of the SDO itself.

The second course would require more independent work by students, focusing on the application of standards. Students would conduct a term-long project, in which they select or develop a product that relates to their field of study, then research the standards applicable to the product. Lectures would be a combination of discussing fundamental methods in finding appropriate standards. Industry representatives would be invited as guest lecturers to instruct about current projects requiring such skills and knowledge. Through a paper and presentation, students would present their findings and provide detailed explanations about why such standards were necessary for the product to operate efficiently and effectively.

However, it is recognized that while a two-term course would be desirable from the authors' point of view, such a commitment might be difficult with many current plans-of-study. As such the modular- or case studies-approach might be a better fit in a particular curriculum.

If a stand-alone course is used, it is proposed that after completion of these courses, students who demonstrated a high level of knowledge about standards be given a precertification in standardization. Depending on the discipline perhaps this certification could be based on existing standards certification programs offered by one or more SDOs. Certification should provide an incentive for students to continue their education about the standardization process. By developing such a course, students would not only be exposed to a variety of standards from multiple fields of study, but also become more knowledgeable about how standards are integrated into everyday products and processes which drive a global economy.

\section{Industrial and educational collaboration}

Based on the survey results, a challenge must be presented to both industrial and educational institutions. Institutions of higher learning are seen as the stepping stone for students prior to entering the competitive work force. Their role is providing the knowledge and skills students need to be an important asset to future employers. It therefore is essential for schools to continue to build relationships with businesses from all economic sectors while developing curriculums focused on common educational goals. Standards are obviously a primary part of any business and if colleges and universities are to develop courses on standardization, a collaborative effort is essential to make required resources available and affordable for students. Since companies depend on colleges and universities to supply employees, standards practitioners and educators 
should not only challenge businesses for more funding support for such courses, but they should also challenge educational institutions to properly support such courses. After all, students of today are leaders of tomorrow.

\section{Conclusions}

Behind every product, service, and business there is a series of standards, without which communication, interchangeability, and world trade would not be possible. This paper details results of a survey to gauge the need for, and interest in, standards education content in higher education. However it is left to later papers to document how the handful of courses noted handle their standards content, or the details of how new courses should be structured.

It seems obvious that there is a gap between the important role of standards in the world, and the amount of education practitioners receive regarding such standards. While standards practitioners recognize the need for multidisciplinary standards education coursework, there are many obstacles to overcome; specifically ways to fund such courses. Despite the fact that company managers seem to agree on the vital role of standards within their organizations, many are hesitant to work with educational institutions, let alone help fund such a course. Without a continuing stream of standards-aware graduates, the world will not operate as we know it today.

\section{Bibliography}

1. American National Standards Institute. (2009). Standards Learn Portal. Retrieved July 10, 2009, from www.standardslearn.org

2. de Vries, H. J., \& Egyedi, T. M. (2007). Education about Standardization: Recent Findings. (K. Jakobs, Ed.). International Journal of IT Standards and Standardization Research, 5

3. International Organization for Standardization (ISO). (2009). ISO Award. Retrieved July 22, 2009, from http://www.iso.org/iso/iso_award_2009.pdf

4. National Institute of Standards and Technology (2009). Promoting Education about Standardization. Washington D.C.

5. Purcell, D. E. (2008). The Strategic Value of Standards Education. Washington D.C.: The Center for Global Standards Analysis.

6. The Center for Global Standards Analysis. (2003). A Standards Education Survey. Washington D.C.: The Center for Global Standards Analysis. 


\section{Appendix A}

\section{Survey Questionnaire}

Do you hold a management position within this corporation, such as plant manager, division supervisor, floor manager, or line supervisor that will enable you to provide accurate answers to a survey about standardization within the company?

1. Please select the sector which best describes the company?

$\begin{array}{lll}\text { Medical } & \text { Automotive } & \text { Military/Government } \\ \text { Aviation } & \text { Construction } & \text { Health/Public Safety } \\ \text { Computer/Electronics } & \text { Alternative Energy } & \text { Other }\end{array}$

2. How important is standardization (both company standards and national/international standards) in the overall growth and success of the company, the processes, the products, etc.?

Extremely Important $\quad$ Neither Important nor $\quad$ Very Unimportant

Very Important Unimportant Not at all Important

3. Does the company offer any courses or opportunities for employees to increase their knowledge about the standards/standardization process?

4. How often are such courses offered?

$\begin{array}{lll}\text { Daily } & \text { Once a Week } & \text { Once a Month } \\ \text { 2-3 Times a Week } & \text { 2-3 Times a Month } & \text { Several Times a Year } \\ \text { Once a Year or Less } & \text { Never } & \end{array}$

5. Do employees attend training sessions offered by external organizations?

6. Is there a need for engineers who possess the fundamentals of standards development and the knowledge to find and apply standards prior to employment?

7. Approximately how many employees work for this company?

8. Who (job title) is responsible for development and compliance with technology standards?

9. Are any employees currently active participants within standards development organizations or active participants on standards committees?

10. Approximately how many employees do so? 
11. How often are employees required to research, locate, and apply standards?

$\begin{array}{lll}\text { Very Often } & \text { Sometimes } & \text { Never } \\ \text { Quite Often } & \text { Rarely } & \end{array}$

12. Are the standards (national or international) required to complete company projects readily available to the employees working on the project?

13. Do current employees meet company expectations when determining what type of standard to use, how to locate the standard, and how to utilize the standard?

14. What types of standards are focused on?

15. Are all employees required to attend these courses?

16. In your opinion would taking a standards education course within colleges, universities, or high schools that focuses on both the development and the application of standards better prepare graduates to work for this company?

17. If such a course was offered and required for students would this potentially reduce the amount of on-site employee training?

18. Would this company be willing to work with local educational institutions to establish a curriculum in which more focus is placed on implementing education about standardization?

19. What types of standards would this company like to see applied within the curriculum to better prepare students for a career with this company or similar companies?

20. What type and approximately how much funding would be available to assist?

21. If a multinational competition were held for students to demonstrate their knowledge about standardization, would this company be willing to help sponsor the competitors?

22. What kind of support would this company be willing to offer?

Facility (web conferences)

Donations (monetary for prizes/scholarships)

Product (awards/prizes)

Internship Positions (winner)

Other 